This item was submitted to Loughborough's Research Repository by the author.

Items in Figshare are protected by copyright, with all rights reserved, unless otherwise indicated.

\title{
Water services regulation for the urban poor: Zambia
}

PLEASE CITE THE PUBLISHED VERSION

http://www.icevirtuallibrary.com/content/serial/wama

\section{PUBLISHER}

(c) Institution of Civil Engineers

\section{VERSION}

VoR (Version of Record)

\section{LICENCE}

CC BY-NC-ND 4.0

\section{REPOSITORY RECORD}

Kayaga, Sam, and Richard Franceys. 2019. "Water Services Regulation for the Urban Poor: Zambia". figshare. https://hdl.handle.net/2134/9703. 
This item was submitted to Loughborough's Institutional Repository (https://dspace.lboro.ac.uk/) by the author and is made available under the following Creative Commons Licence conditions.

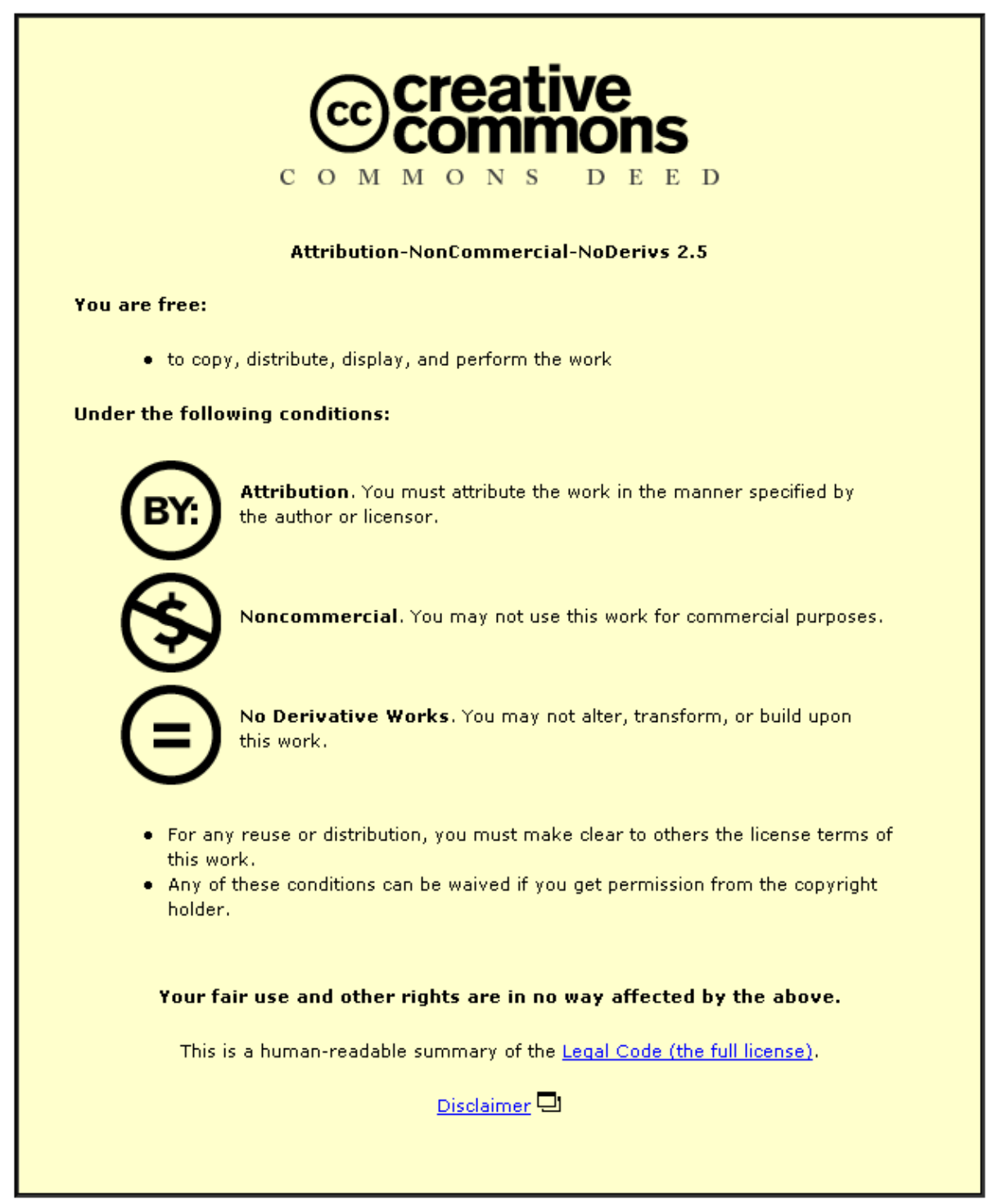

For the full text of this licence, please go to: http://creativecommons.org/licenses/by-nc-nd/2.5/ 


\section{Water services regulation for the urban poor: Zambia}

S. Kayaga MSc(Eng), MSc (DevMgmt), PhD, CEng, MCIWEM and R. Franceys MBA, PhD, Eur Ing, MICE

There is rapid urbanisation in developing countries, where UN Habitat estimates that $\mathbf{8 0} \%$ of the world urban population will live by 2030 . Urban water utilities are facing a challenge of continuously extending services to the rapidly expanding towns and cities, particularly so when most of the population growth is absorbed by slums, leading to an increasing number of the urban poor. Economic regulation of urban water service providers is therefore necessary to guard the equity principle and promote universal water service coverage that is an overarching target for achievement of UN millennium development goals (MDGs). This paper reports on research carried out in Lusaka, Zambia, one of seven case studies in a global research study on whether the needs of the urban poor have been incorporated, as a primary duty of regulation. The study found that NWASCO, the Zambian regulator, has made commendable progress towards 'good regulation' principles of independence, accountability, consistency, transparency, proportionality and equitable targeting of interventions. Clearly, there are good lessons for policy makers in other developing countries to learn from the way regulation structures, systems and procedures were set up in Zambia, and how they have evolved over time. Increased consumer participation will make the regulatory regime more pro-poor.

\section{INTRODUCTION}

The year 2007 has seen a historical urban transition in which for the first time the urban population has exceeded the rural population. ${ }^{1}$ As a result of urban migration and rapid population growth, the world's population living in cities and towns will continue to expand from $3 \cdot 2$ billion people today to nearly 5 billion by 2030 , accounting for about $80 \%$ of the global population. ${ }^{1,2}$ Most of the urban population growth will occur in developing countries, particularly Africa and Asia, where much of the increase is being absorbed by slums. For instance, in sub-Saharan Africa, 62\% of the urban dwellers in 2005 lived in slum conditions, which is defined as lack of at least one of the basic conditions of decent housing-that is, adequate sanitation, improved water supply, durable housing or adequate living space. ${ }^{2}$ It is a great challenge for urban service providers in developing countries to expand their services in tandem with the rapid urbanisation trends, in order to meet the UN millennium development goals (MDGs). For instance, WHO/ UNICEF estimated that the number of urban residents in the developing regions without access to safe water increased from 107 million in 1990 to 170 million in 2004, while for sanitation, the number increased from 475 million to 611 million in the same period. ${ }^{3}$ Most of the unserved are the lowest-income households, categorised as the urban poor, who reside in slums, shanties, unplanned and illegal settlements.

Some of the reasons advanced by urban water utilities for failing to serve the urban poor are: high costs involved in extending services to low-income settlements owing to poor infrastructure planning and difficult topography in those areas of the city; illegal status of the low-income settlements; low ability to pay for the connections; low ability to pay the volumetric water rates; and transient nature of residents of low-income settlements. ${ }^{4}$ Where low-income households are not connected to piped water supply, the poor cannot benefit from the convenience and health benefits of potable water, or from the lower costs. Therefore, unlike residents of low-density well-planned parts of the cities, these urban poor people rarely get full benefits from piped water services. Instead, many consumers in low-income areas rely on alternative small-scale service providers, or water vendors, who are a common sight in many of the cities in developing countries. For various reasons, the prices charged by most vendors are substantially inflated compared with the utility tariffs, sometimes with a multiplication factor as high as 20 times. $^{5}$ Apart from the impact of the doubtful water quality of services supplied by water vendors, the urban poor are doubly negatively affected by meagre quantities of water they are forced to purchase and use, on account of the exorbitant prices.

The provision of water as a basic service is one of the public service obligations required of service providers in developed countries. Public service obligations concern those services that are of public interest, which, under normal circumstances, may not be availed by the service providers if they were to consider only their commercial interests. Certain public services such as drinking water for households qualify for universal service obligations, requiring universal rather than specific coverage, as they are vital for human survival. ${ }^{6}$ The situation is different in developing countries: formal mechanisms by which networked utilities are required to meet the needs of the poor are implicit and unclear. Although there is a general awareness of the ideal of the public service obligation to achieve public health, it is generally assumed that public providers are not required to provide service to 'illegal', low-income settlements in the urban 
areas. The situation in low-income countries needs to change if MDGs are to be met. Apart from social equity reasons, the urban poor deserve disproportionately higher levels of regulatory attention, since they comprise the majority of potential new customers. ${ }^{7}$

Incentive-based economic regulation of water and sanitation providers has proved to be a powerful tool for improving services, particularly but not exclusively in the context of public-private partnerships in developing countries. ${ }^{8}$ Countries of Latin America and the Caribbean established regulatory systems as early as the 1980s and are currently in a post-reform phase of regulatory development. ${ }^{9}$ Other countries that have made tremendous progress in establishment of economic regulation include the Philippines and Indonesia. There are notable examples in these countries where some international private operators have provided differentiated services to low-income settlements, through which the urban poor have benefited significantly. ${ }^{10}$ This development has often happened as a result of the skills of the private operator rather than by way of any clear leadership of government through its agent, the water regulator. ${ }^{8}$

Regulatory systems in developing countries are faced by enormous challenges brought about by both internal and external factors. Weak regulatory capacity and/or external political pressure in developing countries may undermine the regulatory capacity. ${ }^{11}$ In order to strike the right balance between protecting individuals' and utilities' rights, the UK Government has endorsed five principles of 'good regulation': proportionality, accountability, consistency, transparency and targeting of interventions. ${ }^{12}$ Other crucial factors for regulators in developing countries is independence from political pressure, timing of regulatory decisions, regulation of small-scale service providers, and capacity-building for staff working for the regulator. ${ }^{11}$ This paper reports on research carried out in developing countries on systems and structures put in place to regulate water service providers effectively for the benefit of all consumers, particularly the poor.

\section{RESEARCH ON REGULATION FOR THE POOR-THE ZAMBIAN CASE STUDY}

The international research project to investigate existing regulatory systems for urban water services in developing countries was financed by the UK Department for International Development from 2003 to 2005. The overall goal of Knowledge and research project number R8320, which was entitled 'Regulating Public and Private Partnerships for the Poor' was to raise the welfare of the urban poor. Cranfield University in the UK coordinated several international partners that participated in the project. Field research was carried out in Ghana, the Indian state of Andhra Pradesh, Indonesia, Jordan, the Philippines, Uganda and Zambia. The main objectives of the research project were to investigate the present mechanisms for requiring achievement of universal service, provision by the direct provider utility for serving the urban poor, and customer representation in ensuring quality of service delivered. ${ }^{12}$ The current paper presents findings from the case study in Zambia.

\section{I. The study setting}

The water and sanitation sector in Zambia has been undergoing reform since 1993, with the purpose of making direct service provision a responsibility of new institutions that are independent of government, while leaving the Ministry of Local Government and Housing, the lead ministry in the sector, to play the role of policy development, coordination and facilitation for better service coverage. Other key institutions in the urban water sector are the local authorities, who provide water services through established commercial utilities, municipal water/sanitation departments or works departments. As part of the reform process, the National Water and Sanitation Council (NWASCO) was established by the Water and Sanitation Act Number 28 of 1997, and charged with the responsibility of regulating service providers in the urban water and sanitation sector.

Lusaka, the country's capital city, had a population of about $1 \cdot 1$ million at the end of 2000 , of which $60 \%$ lived in peri-urban and low-income settlements. ${ }^{13}$ Officially, provision of water and sanitation services in Lusaka City is the responsibility of Lusaka Water and Sewerage Company (LWSC), a private liability company that is wholly owned by Lusaka City Council. In 2002, non-revenue water in LWSC's operational area was estimated at $52 \%$ of total production, and the utility's service coverage was $34 \%$ of the total population in Lusaka. ${ }^{14}$ By 2006, these performance indicators had improved to 55\% and 65\% respectively. ${ }^{15}$

Many residents of peri-urban areas spend a lot of time collecting water, usually from shallow wells, which is often of poor microbial and physical-chemical quality, resulting in a high incidence of water-borne diseases. ${ }^{3}$ A baseline study carried out in 2005 showed that $65 \%$ and $72 \%$ of the residents in peri-urban areas/low-income settlements do not have access to adequate service levels of water supply and sanitation, respectively. ${ }^{15}$ The government of Zambia developed the national peri-urban water and sanitation strategy in 2001 to improve services to the low-income settlements. ${ }^{16}$ This strategy followed on from the successful implementation of the LWSC peri-urban unit, which was set up in 1995 to cater for the provision of services to 15 of Lusaka's compounds, with an estimated total population of 540000 people at the time of the fieldwork. The management model utilised by the peri-urban unit is tailored to community participation and/or franchising the day-to-day operations to local entrepreneurs duly approved by the community leadership.

\subsection{Data collection methods}

The specific research questions answered by the Zambia case study are listed below.

(a) What is the institutional set-up of the regulator?

(b) Does the institutional set-up foster the regulator's independence, legitimacy, accountability, consistency and transparency?

(c) What is the regulator in Zambia doing to regulate the utility to deliver universal service, particularly to the urban poor?

(d) What mechanisms are in place to ensure participation of the consumers in the regulatory mechanism?

(e) Given the huge service gap caused by the water utility's inadequate capacity to fulfil its mandate in Lusaka, how effective is the regulator in ensuring that alternative service providers deliver adequate levels of service to the large section of the population they serve? 
In order to answer the above questions, data were collected through review of policy and other organisational documents from government, NWASCO (the regulator) and LWSC (the service provider); interviews with 16 key informants from government, NWASCO, LWSC, civil society, community leaders, international development agencies and non-governmental organisation (NGOs); and focus group discussions with key community members (19 men and 34 women selected with assistance from the local community leadership) in a sample of four especially selected locations of peri-urban areas with an estimated total population of 142000 people. Using a generic interview guide, key informants were interviewed for between 1 and $1.5 \mathrm{~h}$ on various regulatory matters in line with their specific roles and functions. Each of the focus group discussions, on the other hand, lasted about $1 \mathrm{~h}$ and covered consumer perceptions of service levels, costs and payment options, disconnection/ reconnection procedures, coping strategies and consumer voice.

\section{FINDINGS AND DISCUSSION}

\section{I. The institutional and organisational set-up of NWASCO}

Comprehensive sector reforms have taken place in Zambia since 1993, with the main objectives of separating water resources management (WRM) from water supply and sanitation (WSS), creation of an independent regulator, and devolution of WSS service provision to local authorities. ${ }^{17}$ NWASCO, which evolved from the Water Sector Reform Support Unit, actively took on the roles and functions of an independent regulator in October 2000. Fig. 1 shows an influence map of how NWASCO interacts with other key organisations in the sector. The mandate of water supply and sanitation in urban areas is vested in the Department of Infrastructure and Support Services (DISS), a department that was established in 1995 within the Ministry of Local Government and Housing. The main functions of DISS are to provide policy direction, mobilise resources and facilitate the development of WSS services devolved to local authorities. ${ }^{17}$ The water sector reform paved the way for fostering infrastructure development in local authorities (LAs), to enable them to provide WSS in their areas of jurisdiction. The LAs were empowered by the Water Supply and Sanitation (WSS) Act Number 28 of 1997 to establish commercial utilities (CUs) or go into joint ventures with private companies to provide WSS services. ${ }^{17}$

In order to separate policy and regulatory functions and therefore minimise political interference, the regulator, NWASCO reports to the national parliament, through the minister of energy and water development. The policy-making body of the regulator is the NWASCO council, which comprises seven members appointed by the minister of energy and water development to represent relevant government departments, civil society organisations and the public. NWASCO secretariat is headed by a director assisted by 14 other permanent staff. ${ }^{15,18}$ Fig. 2 shows the organisational structure of NWASCO in 2006. Not only has the staff continuously obtained training to build technical capacity but NWASCO has recently engaged private consultants located in various towns to improve the regulator's monitoring capacity. ${ }^{15}$

NWASCO's major functions are to advise the government on water and sanitation matters; advise local authorities on commercially viable institutional arrangements for provision of water and sanitation services; license service providers; develop guidelines for technical and financial management of utilities; set up and review tariffs; advise service providers on customer relations management; and disseminate water/sanitation services related information to consumers. The operations of NWASCO are mainly funded by one-off application fees paid by all service providers at the time of application and licence renewal; monthly licence fees paid by all service providers; international technical assistance; and government subvention to plug the budget deficit. NWASCO's financial independence from the government has been improving steadily, from $43 \%$ in 2001 to over $75 \%$ in $2005 .^{14,18}$

\subsection{Regulatory instruments and guidelines}

The WSS Act 28 of 1997 together with subsequent related statutory instruments paved the way for establishment and development of regulatory instruments, structures and procedures. It took about three years for NWASCO to develop

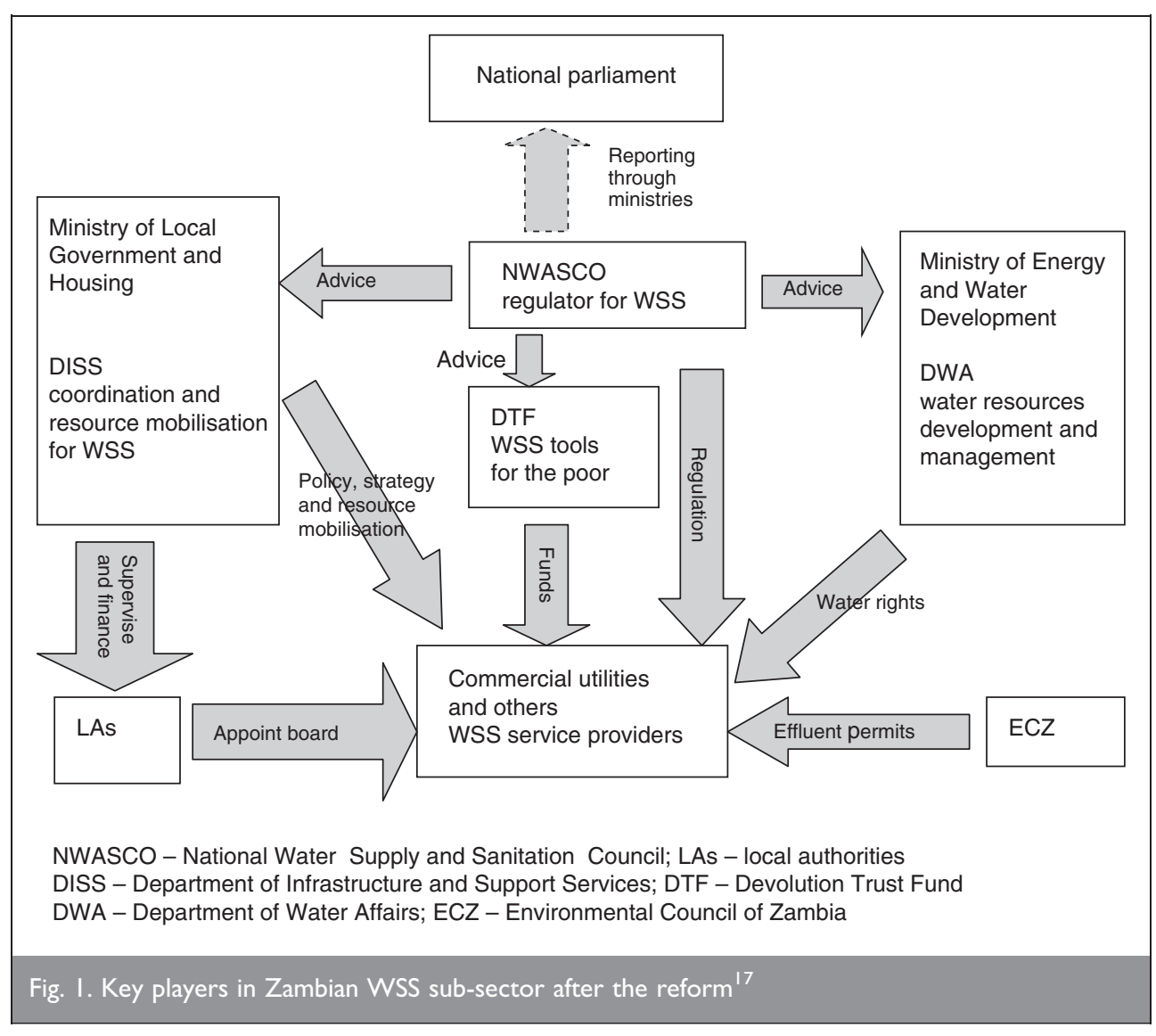




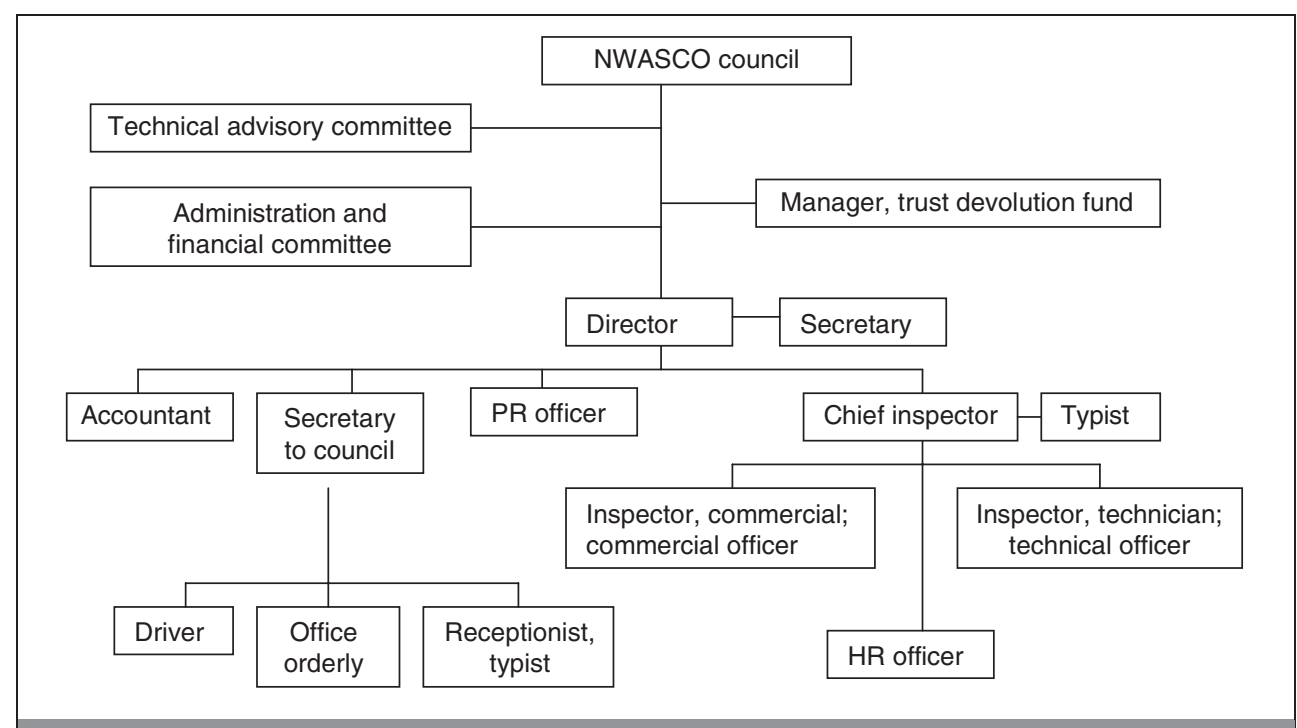

Fig. 2. NWASCO organisational set-up as of $2006^{14,15}$

During the fieldwork, a crosssection of key government officials, professional organisations and the donor community were interviewed, who highly commended the progress NWASCO had so far made in building the foundation for effective regulatory rules, structures and systems. However, many participants of the focus group discussions held in the periurban areas did not know of the existence of the regulator. A few focus group participants had learnt about NWASCO through news clips in the newspapers and electronic media. None of the focus

key elements of the regulatory regime. At the time of the fieldwork, 21 utilities had been granted long-term (ten-year) licences while 26 others were given provisional one-year licences. These utilities were issued with guidelines on topics such as licensing requirements, minimum service levels, business planning, financial projections, investment planning, tariff development and adjustment, corporate governance of commercial utilities, annual organisational reporting, water supply for low-income urban areas, water quality management and human resources management strategy.

After issuing the guidelines and minimum service levels, the regulator implemented a capacity-building programme for relevant utility staff. Service standards for each utility are determined through a negotiation process, and depend on the baseline service levels at the time of application for a licence. Service standards are adjusted periodically through a series of three-yearly service level agreements. Incentives given to utilities for good performance include positive considerations during tariff reviews and in the allocation of performance-based subsidies, as well as better corporate image portrayed through the widely publicised annual performance benchmarks. Penalties range from financial fees, suspension of a service provider, to outright cancellation of a licence.

NWASCO utilises an audit-based regulation approach in which the primary burden of proof is placed on the service provider to demonstrate compliance to standards. Service agreements stipulate that certain minimum information is provided to the regulator on a regular basis. Utilities are therefore required to keep registers on key aspects of technical and functional quality attributes. These data may instantaneously be relayed electronically to the NWASCO information system (NIS) that has continuously been upgraded, and, since 2006, has incorporated a special database on service provision to the peri-urban areas. ${ }^{18}$ The data obtained are checked for accuracy and authenticity, analysed and then utilised to compile the annual urban water sector reports. Most recently, NWASCO has developed a special regulatory supervision (SRS) system, in which providers that show serious weaknesses in their performance are provided with technical assistance, and closely supervised until there is sustainable improvement. ${ }^{15,18}$ group participants had seen or heard about urban water sector reports.

\subsection{Support for extension of services to low-income settlements}

The WSS Act 28 of 1997 requires the regulator to ensure improved service provision to the urban poor. ${ }^{17}$ The devolution trust fund (DTF), which became operational in 1993, was established as a common-pool financing instrument to provide support to service providers to extend services to the urban poor. ${ }^{19}$ The DTF, which is semi-autonomous from NWASCO, is headed by a manager and receives funding from government subvention and external support agencies. Funds are given to eligible utilities for rehabilitation and extension of networks in peri-urban areas; construction of kiosks; software/social aspects such as community sensitisation; and organisational development of peri-urban units. The DTF has developed guidelines on how to plan and implement infrastructure improvements for services enhancement to urban poor settlements. Based on good practices in the country, the DTF is promoting the water kiosk system as an effective method of service provision to the urban poor in the short and medium term. ${ }^{19}$

Utilities access DTF capital on condition that they demonstrate, through a set of criteria, that the funds would be used to extend services to low-income communities in a manner that would foster community participation and promote cost recovery from the users. The funds are disbursed in instalments, upon satisfactory accountability of previous disbursements, to a ring-fenced bank account. DTF monitors the progress of the project through monthly progress reports submitted by the utility, inspections/site visits, and examination of the utility's expenditure against the physical progress. Results from DTF pilot projects implemented since 2003 in six low-income settlements show that the overall objectives were fulfilled, with about 120000 people in low-income settlements accessing safer water supply. ${ }^{20}$ The DTF operations are currently being scaled up to other low-income settlements.

\subsection{The customer's voice}

NWASCO has set up consumer groups known as water watch groups in some service areas, with the main objectives of 
ensuring that consumers' rights are protected, consumers' obligations are explained, consumers' complaints are satisfactorily resolved, and adequate information on utility services is disseminated to consumers. ${ }^{20}$ By 2006, water watch groups (composed of five to eight selected volunteers) in eight towns had been set up. ${ }^{18}$ Lusaka Water Watch Group (LWWG) was formed in 2001 and members, who were selected on the basis that they were knowledgeable and motivated by the interest of working in the water sector, were required to serve for a two-year term.

NWASCO provides LWWG members with stationery, transport and other logistics to carry out the activities. The NWASCO public relations officer is the liaison officer for LWWG. The LWWG members are provided with training to enhance their technical and interpersonal skills. In order to improve their effectiveness LWWG members adopted diversified channels of communication to include use of letters, telephone contacts and consumer general meetings (usually organised during market days), which resulted in an increased number of registered complaints. The LWWG members use civic members in the informal settlements as entry points to community members. The LWWG members discuss issues with resident development committee members (who are elected civic leaders in informal settlements) and/or market management committees prior to holding consumer meetings. Venues for consumer meetings are prioritised according to the number of complaints received from specific areas.

LWWG has made an impact on effectiveness of the consumers' voice in the regulatory regime. Meetings are scheduled in different informal settlements to sensitise the residents regarding their responsibilities and what minimum service levels are expected from LWSC, the utility. In these meetings the utility's representatives participate fully, and are asked to explain their action plans to improve service levels. Through the intervention of LWWG, a number of outstanding complaints are resolved during the meetings or thereafter. The impact of the water watch groups is manifested by the seriousness utilities currently attach to consumer complaints. ${ }^{20}$ Furthermore, collaboration of NWASCO with the Energy Regulation Board (ERB) and Communication Authority of Zambia (CAZ) has led to the transformation of water watch groups into consumer watch groups, hence creating a one-stop centre to cover all customer issues across all the three public utilities. ${ }^{15}$ The first such merger took place in Lusaka in March 2006. ${ }^{15}$

There were a few challenges facing the water watch groups. The level of funding received from NWASCO is inadequate compared with the workload, to the extent that the consumer group was unknown to most people that participated in focus groups held in the low-income settlements of Lusaka. The meagre budget allocations (e.g. total budget for water watch groups in four towns in 2003/2004 was only US\$2000 per quarter $^{20}$ ) limit the scope and depth of activities carried out by water watch groups. Furthermore, there is a question of sustainability of the water watch groups, given that the members were not paid salaries. For instance, at the time of the fieldwork, three places out of the designated membership of eight people were vacant, as those volunteers had 'moved on' to more beneficial occupations. In spite of these challenges, LWWG has remained proactive, constantly reminding service providers of their obligation to provide high-quality services. ${ }^{15}$

\subsection{Alternative service providers}

The WSS Act 28 of 1997 stipulates that LWSC is the designated service provider in the geographical area covered by the boundaries of Lusaka City Council. However, as noted earlier, owing to inadequate capacity of LWSC, it was estimated that only 34\% of residents of Lusaka City were adequately served with water services by $2002 .{ }^{14}$ In response to these poor service levels, a number of international development agencies such as the Japanese International Development Agency, Ireland Aid and Care International have since the early 1990s supported community-based organisations to develop alternative water supply systems (mainly using boreholes) and reticulate these systems to locations in the peri-urban areas, independent of LWSC and other recognised service providers. A typical example is Care International, which supports community-managed water trusts that provide water services to 13 peri-urban areas in Zambia with a total population of about 600000 people. $^{21}$

In spite of the high market share served by independent alternative service providers, they were not directly regulated by NWASCO at the time of the fieldwork. The regulator's official position was that NGO-supported community-managed alternative service points are only a stop-gap measure, and are not a viable and sustainable way of providing services to periurban areas. ${ }^{14,22}$ According to the regulator, all areas under the geographical jurisdiction of a licensed utility are its responsibility and it is held fully accountable for the level of services to these service areas. ${ }^{14}$ Yet, the water utility has no capacity to supervise or to ensure quality assurance in the areas served by the independent alternative service providers. Consequently, at the time of the fieldwork, the communities served by such independent alternative providers were effectively excluded from the benefits accruing from the regulatory regime.

\section{SUMMARY, CONCLUSION AND KEY RECOMMENDATIONS}

The water sector reforms implemented by the Government of Zambia culminated in the enactment of the WSS Act 28 of 1997, which in turn paved the way for establishment of regulatory instruments, structures and procedures. The Act together with its associated statutory instruments provided a good legal framework for development of an effective regulatory regime. NWASCO, the regulator, has gradually developed a regulatory system composed of licensing of service providers, issuing standards, guidelines and a tariff model; the NWASCO information system (NIS), which processes data from the utilities; regular monitoring of service providers; performance measurement and incentive framework; compilation of annual sector reports; special regulatory supervision for low-performance utilities; water watch groups that enhance the customer's voice in the regulatory mechanism; and the Devolution Trust Fund, which supports the utilities in extending services to the urban poor.

The findings of this research show that the operating environment is conducive to the regulator making independent decisions, with minimal interference from the state. The regulator has exploited this environment and made remarkable progress in fulfilling 'good attributes' of regulation. The 
independence is enhanced as NWASCO becomes more financially independent. With increased functionality, the regulator is continuously building legitimacy among key stakeholders, as could be evidenced by the high regard accorded by key government officials, professional organisations and the donor community in Zambia. In order to enhance this legitimacy, the regulator needs to make a stronger partnership with the consumers. Adequate information about the regulatory systems should be disseminated to the consumers, particularly those living in low-income settlements, who are necessarily the biggest beneficiaries of regulation. The information should be in a form that is simple, understandable and accessible to the target audience. This process will empower the consumers and make them active partners in the regulation process.

Structures and systems have been put in place to make the regulator accountable to the state and other stakeholders. However, there is still room to improve accountability to the consumers. For instance, it is important that the influence of the regulator is extended to areas served by independent alternative service providers, who provide water services to over 50\% of Lusaka's population. Such actions will not only promote the principle of accountability to the consumers but also enhance proportionality of benefits to the urban poor. Furthermore, the rights and obligations of the consumers, the major stakeholders in the water sector, and the major beneficiaries of the regulatory regime should be made more explicit through various avenues, such as increased emphasis in the Water Act and service delivery guidelines.

The DTF has already improved the livelihoods of over 120000 people living in low-income settlements. The participation of beneficiary communities in DTF's decision-making process should be increased. This process could be initiated by increasing the participation of the water watch groups that are already very active in consumers' education and sensitisation. There is no doubt that water watch groups have increased consumer representation in the regulator's decision-making processes. More conspicuously, the sensitisation campaigns by water watch groups have led to increased awareness of roles, responsibilities and obligations for both the utilities and the consumers. Furthermore, the transformation of water watch groups into consumer watch groups, to cater for the three utility services of water, electricity and telecommunications is highly commended. Clearly, there are good lessons for policy makers in other developing countries to learn from, in the way that regulation structures, systems and procedures were set up in Zambia, and how they have evolved over time.

\section{ACKNOWLEDGEMENTS}

This document is an output from the UK Department for International Development (DFID) knowledge and research project, contract R8320, a study for the benefit of developing countries. The views expressed are not necessarily those of DFID. The authors are grateful for the efforts of all members of the international research team. Special thanks go to Mr Osward Chanda, the Director of NWASCO, Mrs Astrid Banda, the local fieldwork coordinator, and all the key stakeholders in Zambia.

\section{REFERENCES}

1. UN-Habitat. State of the World's Cities, 2006/7. UN-Habitat, Nairobi, 2006.
2. United Nations. The Millennium Development Goals Report 2007. UN, New York, 2007.

3. World Health ORganisation and UNICEF. Meeting the MDG Drinking Water and Sanitation Target: the Urban and Rural Challenge of the Decade. WHO/UNICEF, Geneva, 2006.

4. Sansom K., Kayaga S., Franceys R., Nuiru C., Coates S. and CHARY S. Serving All Urban Consumers-A Marketing Approach to Water Services in Low- and Middle-income Countries, Book 1: Guidance for Government's Enabling Role. Water, Engineering and Development Centre (WEDC), Loughborough University, UK, 2004.

5. Collignon B. and Vezina M. Independent Water and Sanitation Providers in African Cities. Full Report of a Ten-country Study. UNDP and World Bank Water and Sanitation Programme, Washington DC, 2000.

6. Simmonds G. Universal and Public Service Obligations in Europe. Jan Marchant, Bath, UK, 2003.

7. Bateman J. S., Sohail M. and NJIRU C. Socially sensitive regulation for water services. Proceedings of the Institution of Civil Engineering, Water Management, 2005, 158, No. 4, 177-181.

8. NiCKSON A. and FranceYs R. Tapping the Market: the Challenge of Institutional Reform in the Urban Water Sector. Palgrave, Basingstoke, 2003.

9. United NATIONS. Proceedings of a Seminar on the Regulation of Public Utilities 'Water and Electricity'. Economic Commission for Latin America and the Caribbean, UN, New York, 2007.

10. LAURIE N. and CRESPo C. An Examination of the Changing Contexts for Developing Pro-poor Water Initiatives via Concessions. Final report on DFID SSR Project R7895, 2000. See http://www.ncl.ac.uk/geps/research/publication/24377 for further details. Last accessed 16 February, 2006.

11. NicKSON A. and VARgas C. The limitations of water regulation: the failure of Cochabamba Concession in Bolivia. Bulletin of Latin American Research, 2002, 21, No. 1, 128-149.

12. FranceYs R. Regulating Public Private Partnerships for the Poor. Inception Report for DFI Knowledge and Research Contract R8320, Cranfield University, 2004. See http:// www.silsoe.cranfield.ac.uk/projects/regulation for further details. Last accessed 16 February, 2006.

13. The Government of Zambia. Zambia 2000 Census of Population and Housing. Central Statistics Office, Lusaka, Zambia, 2003.

14. National Water Supply and Sanitation Council. Urban Water Supply and Sanitation Sector Report 2001/2002. NWASCO, Lusaka, 2003.

15. National Water Supply and SANitATion Council. Urban Water Supply and Sanitation Sector Report 2005/2006. NWASCO, Lusaka, 2006.

16. The Government of Zambia. Peri-Urban Water Supply and Sanitation Strategy. Ministry of Local Government and Housing, Lusaka, 2001.

17. National Water Supply and Santtation Council. Water Sector Reform in Zambia. NWASCO, Lusaka, 2005.

18. National Water Supply and Sanitation Council. NWASCO Strategic Plan 2007-2009. NWASCO, Lusaka, 2006.

19. Devolution Trust Fund and German Technical Cooperation (GTZ). Water for the Urban Poor in Zambia: Water Kiosks in Peri-urban and Low-cost Areas. DTF and GTZ, Lusaka, 2005. 
20. National Water Supply and Sanitation Council. Urban Water Supply and Sanitation Sector Report 2003/2004. NWASCO, Lusaka, 2005.

21. Kayaga S. and Kadimba-Mwanamwambwa C. Bridging Zambia's water service gap: NGO/community partnerships.
Proceedings of Institution of Civil Engineers, Water Management, 2006, 159, No. 3, 155-160.

22. NATIONAL WATER SUPPLY AND SANITATION COUNCIL. Urban Water Supply and Sanitation Sector Report 2002/2003. NWASCO, Lusaka, 2004.

\section{What do you think?}

To comment on this paper, please email up to 500 words to the editor at journals@ice.org.uk

Proceedings journals rely entirely on contributions sent in by civil engineers and related professionals, academics and students. Papers should be $2000-5000$ words long, with adequate illustrations and references. Please visit www.thomastelford.com/journals for author guidelines and further details. 